\section{Conflicting terminology in the context of migraine}

Having read the January 2007 issue of the Journal with the very interesting and well-written article on menstrual migraine by Anne MacGregor, ${ }^{1}$ I was surprised to read the words flickering lights (Box 1; 1.2.1 Typical aura with migraine headaches B.1.) in the context of migraines with aura.

This is confusing as the UK Medical Eligibility Criteria for Contraceptive Use ${ }^{2}$ seems to have a different perspective on neurological symptoms and whether these symptoms are classified as typical of aura: they use the words flashing lights and state this is not a symptom of aura.

We have discussed this matter in our Journal Club and would be grateful if this could be clarified

In addition to my query I would like to let you know how much I appreciate your Journal. I thoroughly enjoy reading it, and keeping up to date is a pleasure with your excellent Journal. In addition, I am currently studying for my MFFP Part 2 and feel it is very helpful! I wouldn't want to be without it.

Thanks for all the daily hard work you put into developing the area of Contraception and Sexual Health. It is much appreciated.

Antje Ischebeck, State Exam Witten (Germany), DFFP Career Grade Trainee in Contraception and Sexual Health, Victoria Health Centre,

Nottingham, UK.

E-mail:antjeischebeck@doctors.org.uk

References

MacGregor EA. Menstrual migraine: a clinical review. J Fam Plann Reprod Health Care 2007: 33: 36-47.

Faculty of Family Planning and Reproductive Health Care (FFPRHC). UK Medical Eligibility Criteria for Contraceptive Use (UKMEC 2005/2006). 2006. http://www.ffprhc.org.uk/admin/uploads/298_UKMEC 200506.pdf [Accessed 2 February 2007].

\section{Menstrual migraine}

Thank you for the excellent article on menstrual migraine. ${ }^{1}$ I note some discrepancies between the International Headache Society classification of migraine in the article and information on migraine in the FFPRHC Guidance on 'First prescription of combined oral contraception'. The Guidance tells us: "Symptoms of aura include ... unilateral weakness"; however, the classification states that motor weakness is not a feature of aura (Box 1). Again, the CEU Guidance says: "Flashing lights do not constitute aura" and yet the classification talks of flickering lights being an example of a positive visual symptom in aura. Can you explain these differences?

Anne Donegan, MBChB, DFFP

Sessional Family Planning Doctor, Sexual

Health and Reproductive Care, Coventry, UK.

E-mail:adonegan@doctors.org.uk

Reference

MacGregor EA. Menstrual migraine: a clinical review.
J Fam Plann Reprod Health Care 2007: 33: 36-47.

\section{Reply}

I am grateful to Drs Ischebeck and Donegan for giving me an opportunity to clarify the symptoms of migraine aura and the contraceptive risks, as I know that this is an area of confusion for many of us.

Dr Ischebeck notes that the International Headache Society (IHS) diagnostic criteria for migraine with aura includes 'flickering lights', which conflicts with the UK Medical Eligibility Criteria for Contraceptive Use (UKMEC) and the FFPRHC Clinical Effectiveness Unit Guidance on 'First prescription of combined oral contraception' statement that 'flashing lights are not classified as aura'. ${ }^{1-3}$ The reference quoted by UKMEC refers to the risk of stroke associated with migraine aura and exogenous steroids and does not clarify the symptoms of aura. ${ }^{4}$

In fact, both statements are correct but only if they are taken in full context. The important points when diagnosing aura are not only symptoms, but also the duration and relationship of the symptoms to the headache.

In the FACT Review on 'Hormonal contraception and migraine' that was published in the Journal in 2001, I wrote: “... not all visual disturbances reported by migraine sufferers are aura. A migrainous scotoma is typically a bright spot, which may gradually increase in size to the shape of a letter ' $C$ ', developing scintillating edges that appear as 'zig-zags' (fortification spectra). The aura usually starts at or near the centre of fixation gradually spreading laterally, increasing in size over a period of 5-60 minutes. Generalised 'spots before the eyes', 'flashing lights', blurring of vision, or photophobia of variable duration before or with headache often occur during migraine and are not suggestive of focal ischaemia."5

If 'flashing lights' is taken out of this context it is misleading. UKMEC does state that "aura occurs before the onset of headache" but even this needs further clarification. I suspect UKMEC is trying to distinguish between generalised visual disturbances, which can include 'flashing' or flickering lights' that are normal prodromal symptoms of migraine. These occur up to 24 hours before the onset of headache and can last throughout the attack. They are quite different from the specific visual 'flickerings' of aura, which start before the onset of headache, last up to an hour (usually around 20-30 minutes) and resolve before the onset of headache.

With respect to the FFPRHC statement that "symptoms of aura include ... unilateral weakness", I can confirm that although motor weakness is a feature of the rare dominantly inherited condition 'familial hemiplegic migraine' it is not a feature of typical migraine with aura. If symptoms in the extremities occur during aura, they are sensory, such as pins and needles or numbness, often spreading up one arm and into the face. Sensory symptoms are almost always associated with visual symptoms.

Hence a simple screen for migraine with aura is:

Do you have visual disturbances:

- Starting before the headache?

- Lasting up to one hour?

- Resolving before the headache?

If the answer to all three questions is 'yes', it is likely that the symptoms are aura. 6 Aura can occur without subsequent headache but the nature and duration of the aura is unchanged.

The reason to be concerned about aura is the increasing body of evidence of an increased risk of ischaemic stroke which is greater in women with migraine aura, particularly those using combined hormonal contraceptives (CHCs). Fortunately, since stroke is rare in young women, the absolute risk is very small.

I agree with UKMEC 4 for $\mathrm{CHC}$ use in women with current migraine aura and UKMEC 3 for a past history of migraine aura, although the question raised is how far in the past is a past history? On a pragmatic basis, I have tended to recommend 5 years and I counsel the woman very carefully to stop $\mathrm{CHCs}$ if aura returns. However, Chang et al.'s study suggested increased risk of ischaemic stroke in women with migraine with aura using $\mathrm{CHCs}$ with a past history of even just a single attack with aura. ${ }^{7}$ Donaghy et al. showed increased risk of ischaemic stroke if initial attacks were migraine with aura (OR 8.38, 95\% CI 2.33-30.1) suggesting that even a distant past history is associated with increased risk. 8

As UKMEC recommends, new onset of migraine aura during $\mathrm{CHC}$ use should remain an absolute contraindication to continuing this method but I am unclear why it is UKMEC 3 for continuing progestogen-only methods. I refer to my letter published in the Journal in response to the National Institute for Health and Clinical Excellence (NICE) guidelines on longacting reversible contraception (LARC), in which I noted that in contrast to CHCs there is evidence that use of progestogen-only methods is not associated with increased risk of ischaemic stroke. ${ }^{9}$ Hence, there is no reason why these methods should not be continued if they remain appropriate methods of contraception.

Our role is to help women choose safe and effective contraception. It has been said that "incorrect perceptions of excess risk of contraceptive products may lead women to use them less than effectively or not at all."10 Contraindicating CHCs for women with aura is justifiable since there is evidence of risk and contraceptive efficacy need not be compromised, as other methods are equally, if not more, effective. Since many of these methods are progestogen-only, it would be inappropriate to restrict these in the absence of evidence of harm.

In my earlier letter, I recommended that both NICE and the World Health Organization should consider migraine aura to be Category 2 for both initiation and continuation of all progestogen-only methods. I request that the Faculty of Family Planning and Reproductive Health Care also considers this recommendation.

\section{E Anne MacGregor, MFFP}

Director of Clinical Research, The City of

London Migraine Clinic, London, UK.

E-mail:anne.macrregor@sinoragram.co.uk

\section{References}

Faculty of Family Planning and Reproductive Health Care (FFPRHC). UK Medical Eligibility Criteria for
Contraceptive Use (UKMEC 2005/2006). 2006. http://www.ffprhc.org.uk/admin/uploads/298 UKMEC 200506.pdf [Accessed 2 February 2007]

2 Faculty of Family Planning and Reproductive Health Care (FFPRHC) Clinical Effectiveness Unit. FFPRHC Guidance (July 2006). First Prescription of Combined Oral Contraception (updated January 2007). http://www.ffprhc.org.uk/admin/uploads/538 FirstPrescCombOralContJan06.pdf [Accessed 22 February 2007]

3 Headache Classification Subcommittee of the International Headache Society (IHS). The International Classification of Headache Disorders (2nd edition). Cephalalgia 2004; 24(Suppl. 1): 1-160. Bousser MG, Conard J, Kittner S, de Lignieres B, MacGregor EA, Massiou $\mathrm{H}$, et al. Recommendations on the risk of ischaemic stroke associated with use of combined oral contraceptives and hormone eplacement therapy in women with migraine. Cephalalgia 2000; $20.155-156$.

5 MacGregor EA. Hormonal contraception and migraine FACT Review). J Fam Plann Reprod Health Care

6 Gervil M, Ulrich V, Olesen J, Russell M. Screening for migraine in the general population: validation of a Cephalalgia 1998; 18: 342 Conaghy M, Poulter N, and the World Health Disease and Steroid Hormone Contraception. Migraine and stroke in young women: case-control study. BMJ 1999; 318: 13-18.

8 Donaghy M, Chang $\mathrm{CL}$, Poulter $\mathrm{N}$, on behalf of the European Collaborators of the World Health Organization Collaborative Study of Cardiovascular Disease and Steroid Hormone Contraception. Duration, frequency, recency, and type of migraine and risk of ischaemic stroke in women of childbearing age. J Neurol Neurosurg Psychiatr 2002; 73: 747-750.

MacGregor EA. NICE Guidance on LARC (Letter). J Fam Plann Reprod Health Care 2006; 32: 52 .

10 Gardner J, Miller L. Promoting the satety and use of hormonal contraceptives. J Womens Health (Larchmt) 2005; 14: 53-60. 